\title{
The Improvement of the Operational Characteristics of the Ventilated Front Brake Discs
}

\author{
Denis Boldyrev ${ }^{1, a}$, Maxim Kharchenko ${ }^{2, b^{*}}$, Sergey Nefedyev ${ }^{2, c}$ and \\ Elena Suvorova ${ }^{2, \mathrm{~d}}$ \\ ${ }^{1}$ Togliatti State University, 445020 Togliatti, Russia \\ ${ }^{2}$ Nosov Magnitogorsk State Technical University, 455000 Magnitogorsk, Russia \\ aDA.Boldyrev@vaz.ru, b ${ }^{*}$ kharchenko.mv@bk.ru, cruslan246@mail.ru, dsuvorlen@yandex.ru
}

Keywords: Ventilated Brake Disc, Wear Resistance, Cast Iron, Sulfur Content

\begin{abstract}
Wear and crack resistance are important operational characteristics of brake discs. The paper presents the most optimal concentration of sulfur in cast iron, which ensures its least wear, and discusses the implementation of the front brake discs manufacture from Gh190 cast iron having $0.11 \ldots 0.13 \%$ sulfur content at contrast to the $0.01 \ldots 0.03 \%$ sulfur content, and proves the change leads to a significant increase in wear and frictional properties of the discs. In the course of research, it is found that the increase in the crack resistance of brake discs is possible due to the improvement of the thermophysical properties of cast iron with the increase in the carbon content (up to $3.55 \ldots 3.60 \%$ ) and the decrease in the silicon content (up to $1.45 \ldots 1.50 \%$ ), while the carbon equivalent is constant.
\end{abstract}

\section{Introduction}

The working conditions of car brake discs are considered to be especially difficult. These are caused by the high contact pressures (up to $10 \mathrm{MPa}$ ) and intense frictional heating (up to $600{ }^{\circ} \mathrm{C}$ ), regarding dry abrasive friction [1-4]. An obstacle to further optimization of the materials in the manufacture of the "brake disc - pad" pair is the lack or insufficient information on the influence of the composition and technological factors on the operational properties of the friction pair parts, as well as the information on the mechanisms of friction and wear in the "brake disc - pad" pair [5-9].

The purpose of the work is the improvement of the operational characteristics of ventilated front brake discs by changing the composition of the material used for their manufacture (gray pearlitic cast iron Gh190).

\section{Methods and materials}

The tribotechnical testing of samples made from the materials of the friction pair under study is carried out on a universal machine testing friction and wear according to the "roller - plate" scheme. Samples in the form of plates are made from the materials of the brake pads, and samples in the form of rollers are made from cast iron. The test mode involves: $27 \mathrm{~mm}$ sample diameter; $72 \mathrm{H}$ standard load;3.12 m/s linear velocity; 10 -minute time test. The wear of the cast iron samples is determined by the gravimetric method. Brinell hardness is determined using a TB 5006 device. The ultimate resistance $\sigma_{\mathrm{B}}$ is determined by a TIRA test 2300 machine. The full-scale tests are carried out by an inertial chassis dynamometer system. The test mode for the friction pair under study involves: $\mathrm{J}=4.18 \mathrm{~kg}$ x m2moment of inertia; $\mathrm{N}=200$ number of brakes at each initial heating temperature of the brake disc. The initial temperatures of heating a brake disc before braking are: $100^{\circ} \mathrm{C}, 150^{\circ} \mathrm{C}, 200^{\circ} \mathrm{C}, 250^{\circ} \mathrm{C}, 300^{\circ} \mathrm{Cand} 350^{\circ} \mathrm{C}$; the deacceleration is $\mathrm{j}_{\mathrm{a}}=3 \mathrm{M} / \mathrm{s}^{2}$; the 
frictional torque is $\mathrm{M}_{\mathrm{T}}=38 \mathrm{~kg} \times \mathrm{M}$; the initial braking velocity is $\mathrm{V}_{\text {intitisl }}=100 \mathrm{~km} / \mathrm{h}$; the final braking velocity is $\mathrm{V}_{\text {final }}=60 \mathrm{~km} / \mathrm{h}$.

\section{Results and Discussion}

Gray pearlitic cast iron Gh190 is used for the manufacture of ventilated automobile brake discs. According to its mechanical properties and microstructure it corresponds to the SCh25 grade (1412-85 industry standard). The average chemical composition of Gh190 cast iron in a casting includes $3.3 \ldots 3.4 \%$ of $\mathrm{C} ; 2.1 \ldots 2.2 \%$ of $\mathrm{Si} ; 0.5 \ldots 0.7 \%$ of $\mathrm{Mn} ; 0.1 \%$ of $\mathrm{P} ; 0.03 \%$ of $\mathrm{S} ; 0.1 \ldots$ $0.2 \%$ of $\mathrm{Cr} ; 0.10 \ldots 0.15 \%$ of $\mathrm{Ni} ; 0.45 \ldots 0.50 \%$ of $\mathrm{Cu}(\mathrm{Cu}+\mathrm{Ni} \leq 0.60 \%)$. Let us introduce a conventional value for this chemical composition of cast iron for ventilated brake discs as composition 1.

However, in comparison with cast irons of the same class, Gh190 cast iron has a lower wear resistance. To increase the operational properties and service life of a given part, components increasing its physical, mechanical and tribotechnical characteristics [10] can be added to the cast iron in certain concentrations. In particular, the chemical composition of alternative grades of cast iron contains such a non-scarce element as sulfur.

A comparative wide-ranging analysis of the materials to manufacture ventilated brake discs for some domestic and foreign cars is carried out. Despite the fact that all the ventilated brake discs are made of pearlitic gray cast iron, their chemical composition, microstructure, mechanical and wear-friction properties have significant differences. It is found that, though the strength properties $\left(\sigma_{\mathrm{B}}\right.$ and HB) of gray cast iron for ventilated brake discs of domestic cars are higher in comparison with the materials of the imported ventilated brake discs, the tribological characteristics are noticeably inferior to the latter.

The metallographic analysis shows that manganese sulfides MnS (Fig. 1) play a significant role on the wear-friction properties of gray cast iron. The manganese sulfides appear when sulfur is bound by manganese, having an affinity to it. The influence of sulfur on wear resistance is also studied.

In laboratory tribotechnical tests, the dependence of the wear decrease of Gh190 cast iron and its imported counterparts on the sulfur content is established. With an increase in the sulfur content up to $0.12 \%$, there is a twice increase in its wear resistance.

It should be noted that the sulfur content in the materials of imported ventilated brake discs is in the range of $0.06 \ldots 0.12 \%$. Therefore, to confirm the assumption about the positive influence of sulfur, experimental melting of brake discs are carried out, the controlled sulfur content in cast iron are: $0.03 \%, 0.10 \%, 0.12 \%$ and $0.13 \%$ respectively.

According to the results of the comparative laboratory tribotechnical tests of samples made from experimental castings of ventilated brake discs, the optimal concentration of sulfur is determined. The least wear of the material (up to 2 times) corresponds to the sulfur content of 0.11 $\ldots 0.13 \%$, which verifies the results obtained in the study of imported analogues. The higher is the sulfur content, the greater is the amount and size of $\mathrm{MnS}$. On the one hand, manganese sulfides act as a solid lubricant. On the other hand, when the sulfur content is over $0.13 \%$, the coarsening of sulfides occurs, which negatively affects the contact strength of the surface [11]. 


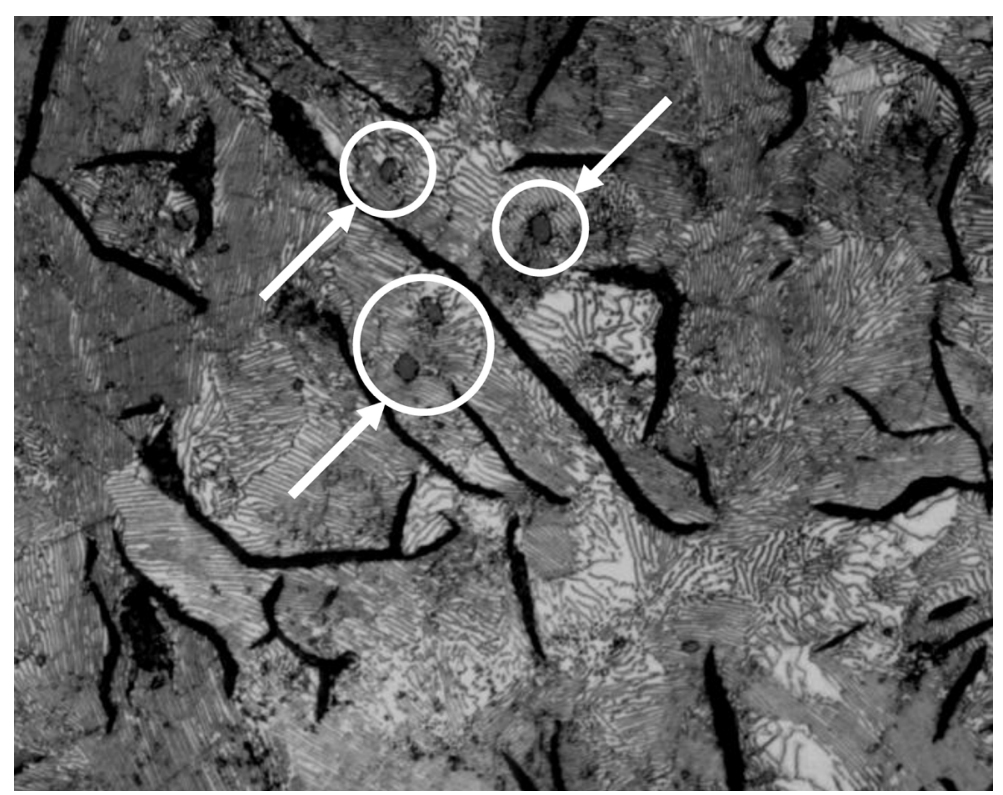

Fig. 1. Microstructure of Gh190 cast iron, when the sulfur content is 0.12\% (x500) (manganese sulfide inclusions are indicated by arrows)

Bench true-to-life tests on the experimental ventilated brake discs show that the increase of the sulfur concentration in gray pearlitic cast iron Gh190 to $0.12 \%$, when the manganese content is constant, makes it possible to increase the wear resistance of ventilated brake discs and to reduce the increase in the thickness variation by $30 \%$ respectively, taking into consideration that it directly influences the negative operational effect "vibration at braking"[11]. Let us designate this chemical composition of cast iron for ventilated brake discs as composition 2.

On the one hand, the decrease of the negative operational effect "vibration during braking" is associated with the decrease in the growth of the thickness difference of the working surfaces of the brake disc. On the other hand, it is caused by the improvement of the vibration-absorbing properties of cast iron. Regarding that cast iron is inherently a material with a pronounced heterogeneous structure (it has a metal matrix and graphite inclusions), it becomes clear that with the increase of sulfur content in gray cast iron (above $0.04 \ldots 0.05 \%$ ), the appearing spherical manganese sulfide inclusions become additional structural components that enhance the damping properties of the cast iron. The mechanism for increasing the damping capacity of the cast iron with additional inclusions lies in the occurrence of local plastic deformation in the inclusion sat the soft plastic phase, that are manganese sulfides, as well as at the interphase boundary "manganese sulfide - perlite" [12].

The necessity to implement the 2 nd stage of the research is due to the fact that ventilated brake discs are inferior in crack resistance to non-ventilated, solid brake discs. Due to the presence of cavities between the stiffening ribs, ventilated brake discs have improved cooling properties, but this factor, as a rule, also causes the appearance and spreading of cracks on the working surfaces of the disc when there is a lack of thermophysical characteristics of the material.

When developing cast iron for brake discs, one of the main requirements is to obtain the lowest tendency to crack. It is known that the properties of cast iron are determined by the content of carbon and silicon, as well as by a value which characterizes their combined content as a carbon equivalent [13]: 


$$
C_{\ni}=\% C+\frac{\%(S i+P)}{3}
$$

where $C$ is carbon content, \%; Siis $\mathrm{Si}$-content, \%; Pis P-content, \%.

Gray cast iron with lamellar graphite, having a constant carbon equivalent, possesses improved thermophysical characteristics (thermal conductivity, coefficient of linear expansion) with an increased content of free graphite and a decreased content of silicon [14]. At the same time, a decrease of the silicon content in the metal matrix makes it possible to weaken the process of graphitization of cast iron during heating and to increase the ferrite content.

In the range of carbon content from 3 to $4 \%$ and silicon from 1 to $3 \%$ [15], the thermal conductivity of cast iron, $\lambda, W(m \cdot K)$, can be accurately estimated using the following regression equation:

$$
\lambda=17,4(\% \mathrm{C})-6,3(\% \mathrm{Si})
$$

Thus, the increase in the fracture toughness of ventilated brake discs is possible due to the improvement in the thermophysical properties of cast iron with the increase in the carbon content and the decrease in the silicon content, when the carbon equivalent is constant. The optimization of the carbon equivalent of cast iron involves the correct balance of carbon and silicon content. It is verified that the higher is the carbon content and the lower is the silicon content, the greater is the strength and thermal conductivity, and due to this, the crack resistance of cast iron is better while its other characteristics and indicators are the same. The mechanism of this phenomenon is explained by the depletion of pearlite silico ferrite in silicon with a simultaneous increase in the content of free graphite, which has a beneficial effect on both the thermophysical (due to the high thermal conductivity of graphite and ferrite with a low silicon content) and the wear-frictional properties of cast iron (due to the reduced brittleness of ferrite with a low silicon content and a high content of free graphite, being a solid lubricant).

It is known that the reduction of the carbon equivalent in gray cast iron implies the use of higher grades. In this case, under the same conditions of the smelting process, the structure of gray iron undergoes qualitative changes. increase in the base metal content in gray cast iron at one and the same cooling velocity causes free cementite (chill) to appear. During the experimental work it is found that the decrease in the silicon content from $1.30 \ldots 1.62 \%$ to $0.95 \%$ regarding a relatively constant carbon content $(3.30 \ldots 3.39 \%)$ dramatically changes the morphology of graphite inclusions. If uniformly distributed (type A) and rosette (type B) and interdendritic non-directional (type D) graphite inclusions initially prevail in cast iron, then the lack of silicon results in the shift of the types of graphite, they change their places, types B and D prevail, while type A is present.

Thus, during the experimental work, it is found that in practice the silicon content in the casting should not be lower than $1.3 \%$ in order to avoid the appearance of structurally free cementite (chill) in the cast iron structure. After carrying out a complex of studies of standard $\varnothing 30 \times 220 \mathrm{~mm}$ samples, a work program is prepared and implemented to develop the smelting technology and optimize the carbon equivalent of gray cast iron of the pearlitic class Gh190 for ventilated brake discs.

The purpose of the research at this stage is to change the content of carbon and silicon in cast iron within the range of $3.55 \ldots 3.60 \%$ of $\mathrm{C}$ and $1.45 \ldots 1.50 \%$ of $\mathrm{Si}$, regarding a constant carbon equivalent and the same content of other elements, in order to increase the operational characteristics of brake discs. A pilot lot of ventilated brake disc castings have the following actual 
chemical composition of cast iron: $\mathrm{C}-3.59 \%, \mathrm{Si}-1.46 \%$; $\mathrm{Mn}-0.64 \% ; \mathrm{P}-0.034 \% ; \mathrm{S}-0.134 \%$; $\mathrm{Cr}-0.12 \% ; \mathrm{Ni}-0.13 \% ; \mathrm{Cu}-0.53 \%$. Let us designate it as composition 3.1 .

Comparative bench true-to-life tests of experimental ventilated brake discs and discs made from Gh190 cast iron having $0.12 \%$ sulfur content show an additional reduction in the wear of the experimental brake disc by $10 \%$. Consequently, the increase in the wear resistance of the experienced ventilated brake discs in comparison with the serial ones made of Gh190 cast iron with a low sulfur content (up to $0.03 \%$ ) accounts for $40 \%$.

With a satisfactory value of thermal distortion and according to the results of the tests with the experimental ventilated brake discs, no cracks of a length exceeding $10 \mathrm{~mm}$ are found, and no through cracks are found as well. Thus, the results obtained during the tests show that the experienced ventilated brake discs have advantages in wear resistance and resistance to fatigue cracking.

However, in practice, the achievement of such carbon and silicon content in ventilated brake disc castings requires strict adherence to all technological parameters of smelting and modification of cast iron, that is why, manufacturer 1 refuses to introduce the worked out chemical composition of cast iron.

To eliminate the demonopolization of the supply of ventilated brake discs, a work with manufacturer 2 is carried out to optimize the chemical composition of brake discs in order to increase the stability of the technological process and improve the complex of operational characteristics of brake discs. Taking into account the peculiarities of the used charge materials for smelting, the following chemical composition of cast iron is proposed: $\mathrm{C}-3.55 \ldots 3.60 \%, \mathrm{Si}-$ $1.85 \ldots 1.90 \%$; Mn- $0.50 \ldots 0.55 \% ; \mathrm{P}-0.1 \% ; \mathrm{S}-0.11 \ldots 0.13 \% ; \mathrm{Cr}-0.1 \% ; \mathrm{Ni}-0.05 \% ; \mathrm{Cu}-0.65$ ... $0.70 \%$. Let us designate it as composition 3.2 .

The results of the bench true-to-life tests show that the experienced ventilated brake discs in comparison with the serial brake discs made of Gh190 cast iron with a low sulfur content (composition 1) have 40\% lower wear. Thus, composition 3.1 and composition 3.2 for ventilated brake discs can be considered equivalent in terms of wear resistance.

Ventilated brake discs of composition 3.2 have the same thermal distortion and crack resistance as those of brake discs of composition 3.1. Consequently, these compositions of ventilated brake discs can be considered equivalent in terms of thermophysical characteristics. A higher silicon content and a lower nickel content in composition 3.2 compared to composition 3.1 is compensated by a lower content of manganese, chromium and a higher content of copper.

The consistent development of the chemical composition of the cast iron of ventilated brake discs to improve the operational characteristics of the brake discs is shown in the diagram (Fig. 2).

Increased performance of brake discs

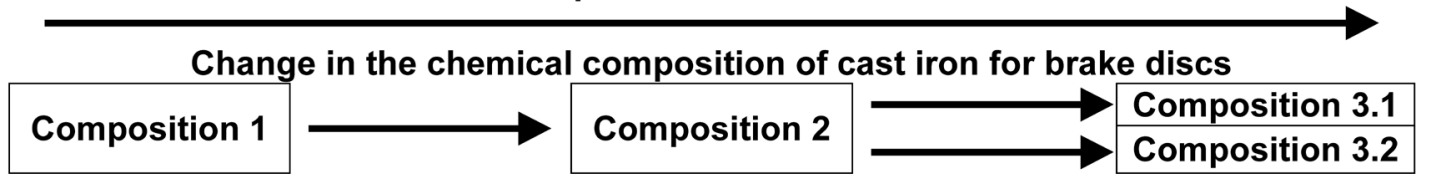

Fig. 2. The diagram of improving operational characteristics of brake discs

\section{Conclusion}

The optimal concentration of sulfur in cast iron is determined, which ensures its lowest wear (composition 2). The manufacture of front brake discs from Gh190 cast iron with a sulfur content of $0.11 \ldots 0.13 \%$ instead of $0.01 \ldots 0.03 \%$ is introduced, and it results in a significant increase in wear and friction properties. According to the results of bench tests showing satisfactory crack 
resistance, the decrease in the wear rate and the increase in the thickness difference of the brake discs is $30 \%$.

It is established that the increase in the crack resistance of brake discs is possible due to the improvement in the thermophysical properties of cast iron with the increase in the carbon content (up to $3.55 \ldots 3.60 \%$ ) and the decrease in the silicon content (up to $1.45 \ldots 1.50 \%$ ) when the carbon equivalent (composition 3.1) is constant. The mechanism of this phenomenon lies in the depletion of pearlite silico ferrite with silicon while having a simultaneous increase in the content of free graphite, which has a beneficial effect both on the thermophysical (due to the high thermal conductivity of graphite and ferrite with a low silicon content) and the tribotechnical properties of cast iron (due to the reduced brittleness of ferrite with low content of silicon and a high content of free graphite, being a solid lubricant).

The chemical composition of cast iron for ventilated brake discs is optimized (it is composition 3.2), which makes it possible to obtain the same level of wear (up to 40\%) and thermophysical properties (as for composition 3.1) due to the difference in the content of silicon, manganese, chromium, nickel and copper. This chemical composition is used for the manufacture of cast blanks for ventilated brake discs.

\section{Acknowledgments}

This work is carried out within a framework of the government order (No. FZRU-2020-0011) of the Ministry of Science and Higher Education of the Russian Federation.

\section{References}

[1] M.J.Haigh, H.Smales, M. Abe, Vehicle judder under dynamic braking caused by disc thickness variation, ImechE, C444/022 (1993) 247-258.

[2] G. Gigan, V. Norman, J. Ahlström, T. Vernersson, Thermomechanical fatigue of grey cast iron brake discs for heavy vehicles, Proc. of the Institution of Mechanical Engineers, Part D: J. Automobile Engineering, 233(2) (2017) 453-467. https://doi.org/10.1177/0954407017739723

[3] S.B. Istoc, H. Winner, Heat cracks in brake discs for heavy vehicles, Automotive and Engine Technology, 3 (2018) 61-68. https://doi.org/10.1007/s41104-018-0027-y

[4] F. Bagnoli, F. Dolce, M. Bernabei, Thermal fatigue cracks of fire fighting vehicles gray iron brake discs, Engineering Failure Analysis, 16(1) (2009) 152-163. https://doi.org/10.1016/j.engfailanal.2008.01.009

[5] D.A. Boldyrev, R.R. Dema, O.B. Kalugina, The microstructure and hardness of casting a solid brake disc after late graphitizing modification IOP Conf. Series: Materials Science and Engineering, 966 (2020) 012021. https://doi.org/10.1088/1757-899X/966/1/012021

[6] D.A. Boldyrev, A.N. Shapovalov, S.P. Nefedev, R.R. Dema, V.N. Kononov, M.V. Kharchenko, E.V. Suvorova and I.Yu. Markova, The electron-microscopic and X-ray spectral analysis of phase composition of CGI inoculant structure, J. Chem. Technol. Metall. 54 (2019) 348-361.

[7] D.A. Boldyrev, S.I. Platov, N.V. Urtsev, D.V. Terentyev and O.R. Latypov, Research and features of preliminary graphitizing processing of melt of iron with silicon carbide on the structure and properties of cast iron castings, IOP Conf. Series: Materials Science and Engineering, 1008 (2020) 012047. https://doi.org/10.1088/1757-899X/1008/1/012047 
[8] Erokhin Yu.V., Zakharov A.V., Leonova L.V. Izuchenie veshchestvennogo sostava shlakov proizvodstva vanadievogo chuguna alapaevskogo metallurgicheskogo zavoda, Vestnik of NMSTU 18(2) (2020) 13-21. https://doi.org/10.18503/1995-2732-2020-18-2-13-21

[9] V.A. CHajkin, D.A. Boldyrev, N.V. CHajkina, Osobennosti grafitiziruyushchego modificirovaniya vysokoprochnogo chuguna smesevymi modifikatorami v usloviyah OAO "AVTOVAZ", Vestnik of NMSTU, 4 (2007)53-58.

[10] A.P. Gulyaev, Metallovedenie, Mashinostroenie, Moscow, 1977.

[11] D.A. Boldyrev, Povyshenie rabotosposobnosti i resursa pary treniya «tormoznoj disk kolodka», PhD thesis, Togliatti, Russia, 2004, 26 p.

[12] M.S. Blanter, Yu.V. Piguzov, Metod vnutrennego treniya v metallovedcheskih issledovaniyah, Metallurgiya, Moscow, 1991.

[13] A.D. Sherman, A.A. Zhukov, CHugun, Metallurgiya, Moscow, 1991.

[14] K.Bungardt, W.Spyra, Wärmeleitfähigkeit von legierten und unlegierten Stählen und Legierunden bei Temperaturen zwischen 20 und $700^{\circ} \mathrm{C}$, Arch. Eisenhüttenwesen, 26 (1971).

[15] D.Severin, U.Franke, M.Lampic, Steigerung der Lebensdauer von Bremsscheiben, ATZ,11 (2002) 1016-1023. https://doi.org/10.1007/BF03223482 